
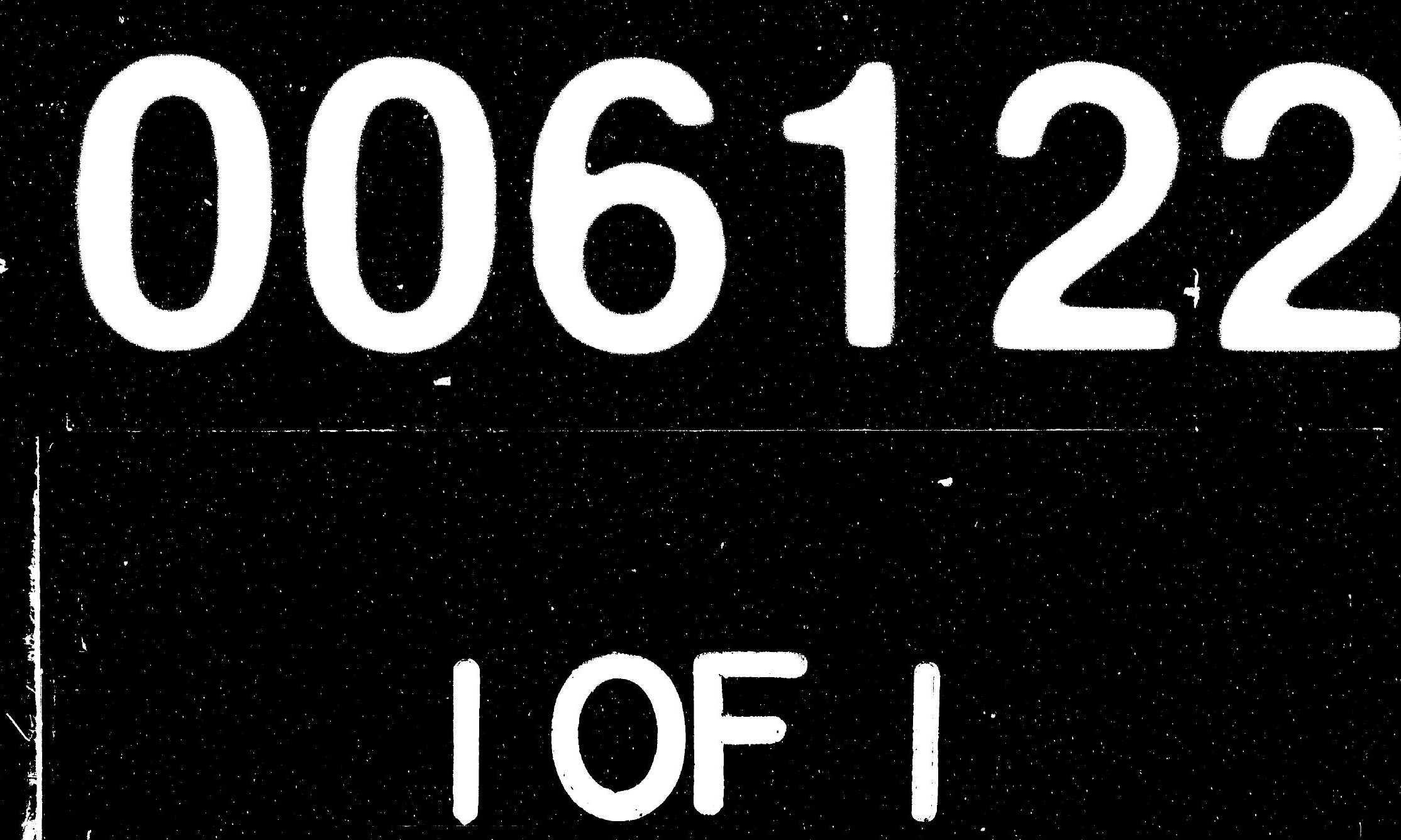

$d$

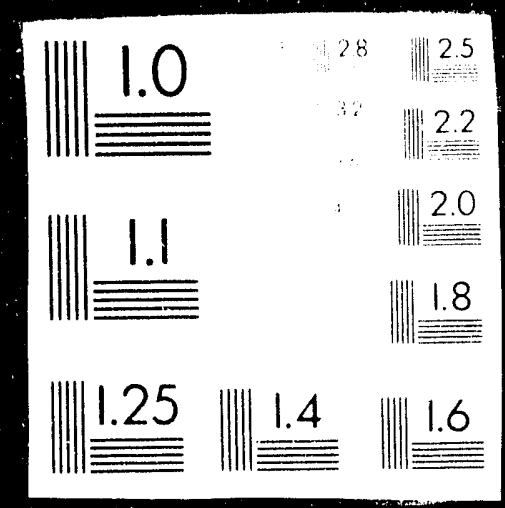

a 


\title{
THE ROLE OF ANALYTICAL MODELS: ISSUES AND FRONTIERS
}

\author{
EMF WP 10.2
}

Peter Blair

March 1991

\section{DISCLAIMER}

\begin{abstract}
This report was prepared as an account of work sponsored by an agency of the United States Government. Neither the United States Government nor any agency thereof, nor any of their employees, makes any warranty, express or implied, or assumes any legal liability or responsibility for the accuracy, completeness, or usefulness of any information, apparatus, product, or process disclosed, or represents that its use would not infringe privately owned rights. Reference herein to any specific commercial product, process, or service by trade name, trademark, manufacturer, or otherwise does not necessarily constitute or imply its endorsement, recommendation, or favoring by the United States Government or any agency thereof. The views and opinions of authors expressed herein do not necessarily state or reflect those of the United States Government or any agency thereof.
\end{abstract}

\section{Energy Modeling Forum}

Terman Engineering Center

Stanford University

Stanford, California 


\section{THE ROLE OF ANALYTICAL MODELS: ISSUES AND FRONTIERS}

\section{INTRODUCTION}

A number of modeling attempts to analyze the implications of increasing competition in the electric power industry appeared in the early 1970 s and occasionally throughout the early $1980 \mathrm{~s}^{1}$. Most of these of these analyses, however, considered only modest mechanisms to facilitate increased bulk power transactions between utility systems. More fundamental changes in market structure, such as the existence of independent power producers or wheeling transactions between customers and utility producers, were not considered.

More recently in the course of the policy debate over increasing competition ${ }^{2}$, a number of models have been used to analyze alternative scenarios of industry structure and regulation. In this Energy Modeling Forum (EMF) exercise, we attempted to challenge existing modeling frameworks beyond their original design capabilities. We tried to interpret alternative scenarios (see Table 1) or other means of increasing competition in the electric power industry in the terms of existing modeling frameworks, to gain perspective using such models on how the different market players would interact, and to predict how electricity prices and other indicators of industry behavior might evolve under the alternative scenarios.

We recognized from the outset that few, if any current electricity market models are capable of accommodating comprehensively many of the key features of the current competitive trends in the U.S. electricity market, including: (1) competition in generation, especially between utilitics and non-utility sources and (2) transmission activity generated by competition, (3) and

${ }^{1}$ These include Joskow, P. and R. Schmalansee, Markets for Power: An Analysis of Electrical Utility Deregulation, Cambridge, MA: MIT Press, 1983 and Hobbs, B. and R. Schuler, "Electric Utility Deregulation: Estimated Price and Welfare Consequences," Annual Meeting of the American Association of the Advancement of Science, Detroit, MI, May 31, 1983.

${ }^{2}$ The policy debate centers around the 1988 FERC proposed rulemakings on competitive bidding procedures and on various State and utility proposals to increase the use of independent power production in providing new sources of electricity supply. 

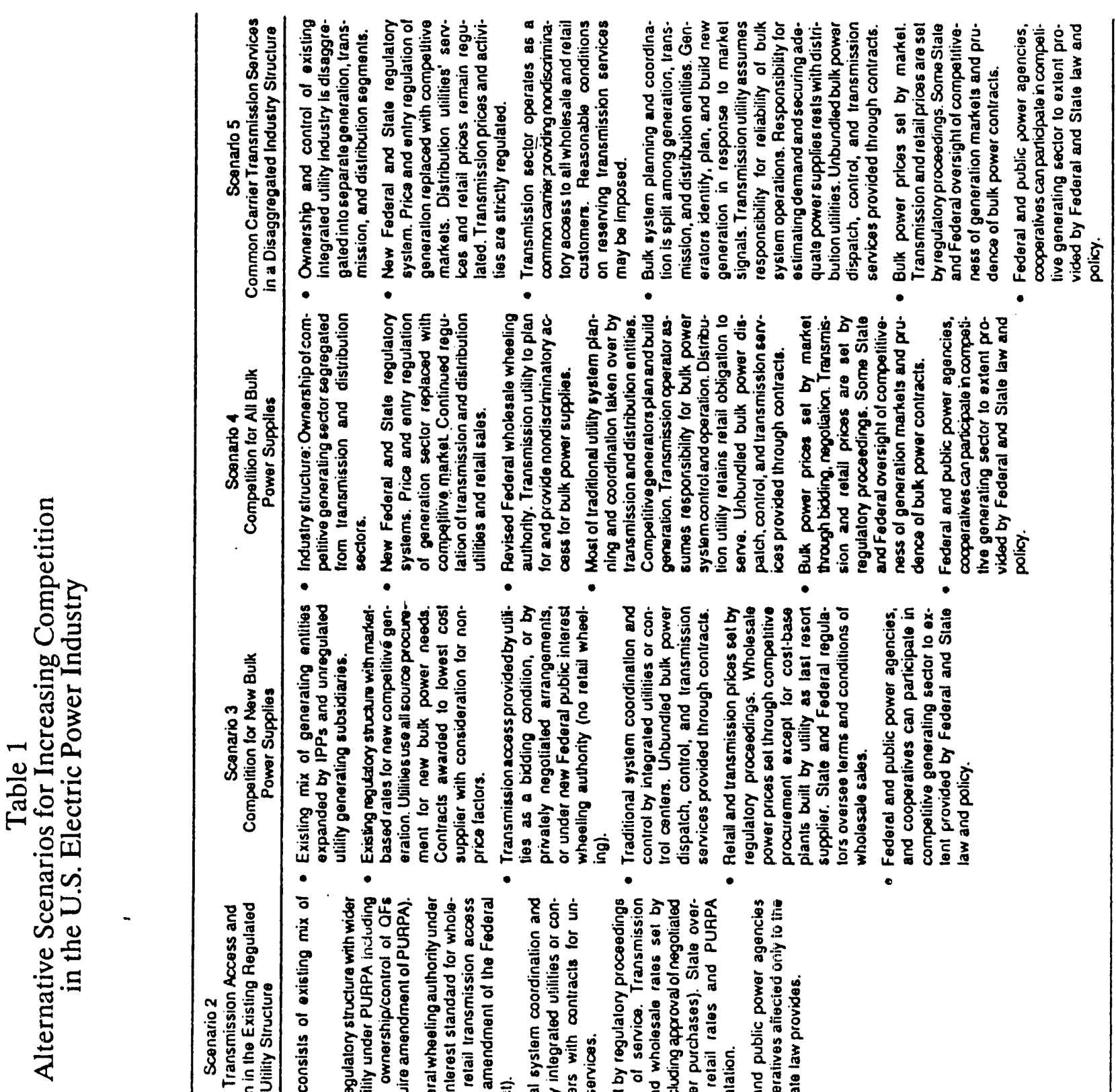

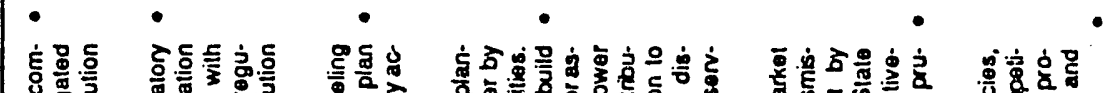

差荡

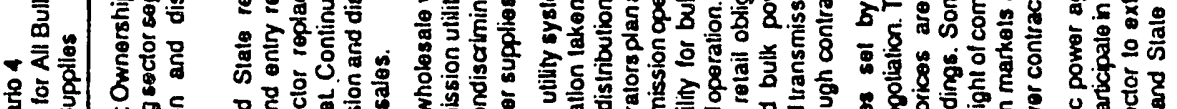

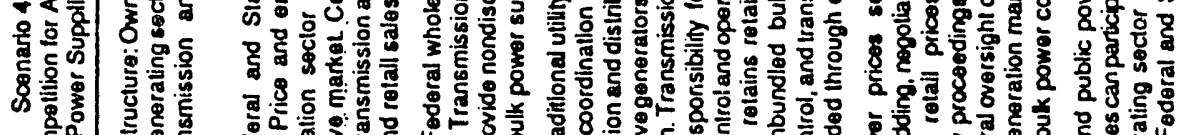

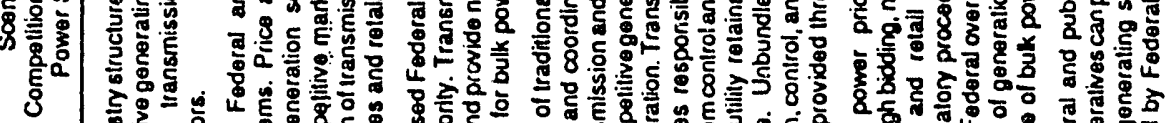

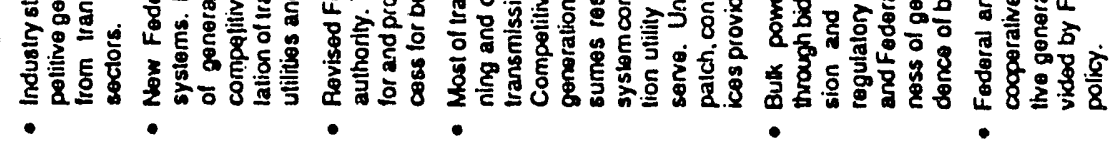

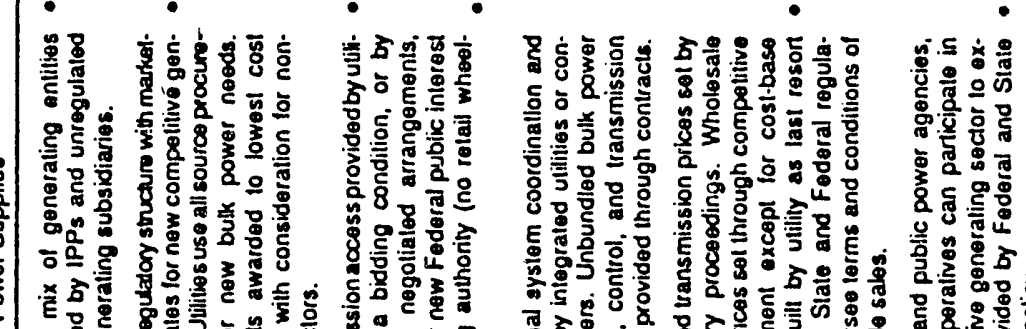

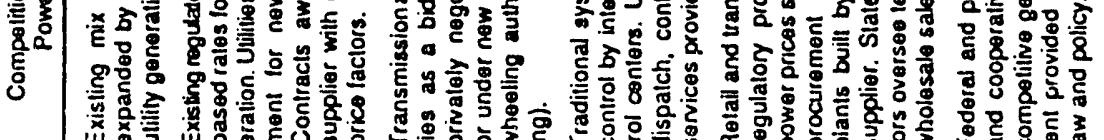

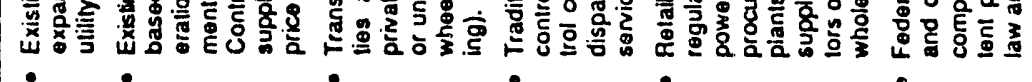

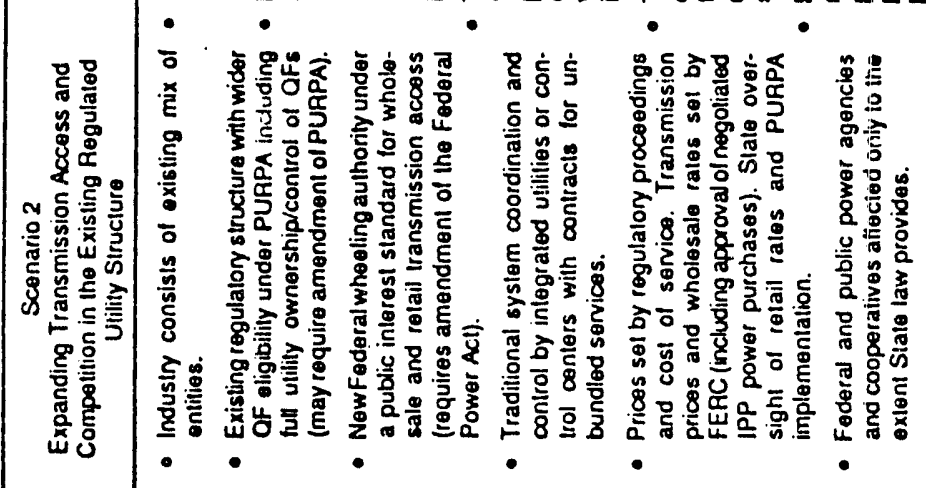

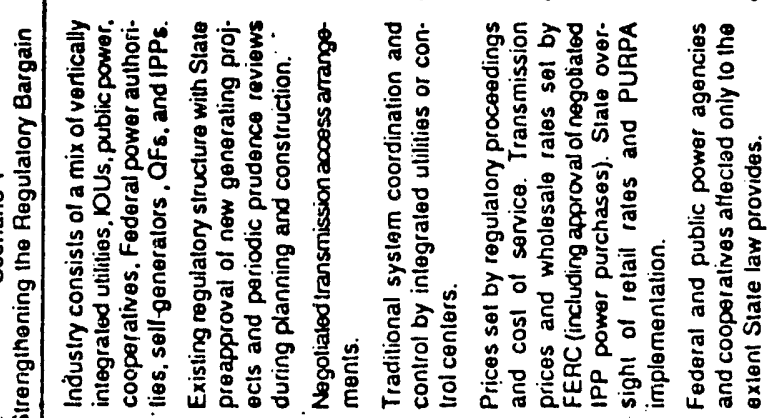


competition among retailers in scenarios allowing retail wheeling of electricity. Nonetheless, some important insights with existing models were possible.

\section{ALTERNATIVE MODEL PARADIGMS}

Models used in the electric power business span the spectrum of disciplines from basic sciences, to engineering, to operations research, to economic policy models and econometrics. The dramatic changes in the industry over the last decade have prompted development of these models, particularly as utilities and other market players search for ways to analyze and plan in the face of heightened technical, economic, and regulatory uncertainties.

Traditionally the vast array of engineering models used in the electric utility industry in areas such as generation and transmission reliability analysis or load flow have seldom been important in policy analysis. Planning models such as production costing or generation planning are usually approximated in some way in policy models. More recently efforts to systematically incorporate load management and conservation in "least cost" planning models have challenged these planning models, particularly in dealing with uncertainty. Nonetheless, approximations of many system planning and operations functions are likely to become increasingly important as policy models are employed in analyzing economic and regulatory scenarios that could have significant impacts on power system operation and control. For example, transmission planning and utilization may become very important features of the next generation of policy planning models, especially if access to transmission services becomes available to a wider range of market players. Some existing models approximate transmission capacities and constraints as a linear transportation problem but are unable to capture the complexities of system constraints such as voltage support or reactive power control.

Most policy-oriented electricity models and system planning models can only roughly approximate transactions involving interconnection with neighboring utilities. For example, 
multiple area dispatching production costing models that can account for purchases from neighboring utilities and the associated transaction cost and impact on transmission utilization are not generally used by utilities themselves, let alone policy analysts. One such model developed by General Electric is only used on a sporadic basis by a small number of utilities to date, largely because the data requirements are so extensive (see Box A).

\section{BOX A \\ OVERVIEW OF THE GENERAL ELECTRIC MULTI-AREA PRODUCTION SIMULATION MODEL}

Although the use of transfer limits in multi-area models was a significant improvement over single area models, the simulation of power exchanges on the actual transmission system was not accurately modeled. Within an area, the transmission system was modeled as having infinite capacity and between areas transfers were limited by single constraints, rather than being functions of the transmission system configuration. To improve the simulation, a methodology was implemented utilizing distribution factors derived from ac power flow data, to represent the flows on all the key transmission lines in the system. Distribution factors define how the output of a generator will be distributed among the transmission lines within a power system.

The distribution factor procedure, developed by the New York Power Pool, is the basis for the transmission methodology used in GE's Multi-Area Production Simulation (MAPS) program. This methodology allows simultaneous consideration of both pre- and post-contingency conditions of the transmission system, recognizing transmission line limits in a "secure" economic dispatch. As units are loaded, the power flows on the transmission lines are computed using the distribution factors. Once the limit of a transmission line is exceeded, a least-cost modification to the unit dispatch is used to relieve the overload. The dispatch process is then continued.

When using MAPS, transmission lines can be assigned summer and winter ratings, normal, long-term emergency (LTE), and short-term emergency (STE) ratings. The transmission line limits may be based on thermal ratings, voltage considerations, or stability considerations. The power and angle limitations of phase angle regulators can also be specified. Lastly, MAPS is able to calculate transmission losses during dispatch according to the actual transmission line loadings.

Although MAPS provides a promising methodology for handling transmission constraints, its data requirements are substantial. It has been applied to electric systems with 2200 buses and 4000 lines. Whether the approach can be used in a national electricity market model is an open question. Feasibility will depend on the number of key transmission lines and the availability of appropriate data; determining the level of aggregation that preserves the accuracy of the methodology, while being feasible from a data availability and computational standpoint is itself a major research area. 
Most current electricity market models are industrial organization models structured to characterize the likely evolution of markets. They are often implemented through linear programming, or other optimization techniques, or in some cases simple screening procedures to match supplies with demands at lowest cost. They often include detailed inventories of existing generating capacity, characterizations of cost and performance of future generating options, and assumptions of future load growth. Transmission costs are generally included only as bundled with alternative generating options so that separate transmission investments cannot be analyzed. Similarly, until recently, demand side options were considered only as an adjustment to the demand curve, i.e., as a constraint rather than as a variable in optimization. Only the largest market models include features of "price feedback" to account for the price elasticity of demand for electricity or of major fuels such as coal or natural gas. Many models attempt to have fairly sophisticated econometric characterizations of demand for electricity as a function of economic activity.

\section{SOME SPECIFIC EXAMPLES}

The experiences of a number of models were reviewed and discussed in the course of the EMF effort. These included the DRI/McGraw Hill Electricity Markets Model ${ }^{3}$ used by the DRI in their Electricity Services Practice; the AES FOSSIL2 ${ }^{4}$ model used by the U.S. Department of Energy and Applied Energy Services Corporation (AES), an independent power producer and consulting services firm, in various planning activities; ICF, Inc. ${ }^{5}$ which attempted to assess the environmental implications of the notices of proposed rulemaking set forth by the FERC in 1988;

${ }^{3}$ Larry Makovich, "DRI Energy Analysis of OTA's Deregulation Scenario 4: All Source Competition for All Bulk Power Supplies with Generation Segregated from Transmission and Distribution Services," DRI Energy Group, Lexington, MA, February 22, 1988.

${ }^{4}$ Fossil2 reference.

${ }^{5} 1988$ reference for EIS. 
a model developed by Wharton Econometric Forecasting Associates ${ }^{6}$ for use in regional electricity market analysis, and the Energy Information Administration's model of non-utility power production. ${ }^{7}$

In the EMF exercise two of these models, the DRI and AES models, were used to try to characterize the implications, principally on electricity prices, of alternative economic and regulatory scenarios.

\section{DRI Model}

The DRI/McGraw Hill Electricity Model is a multiregional electricity market model, combining U.S. Census and National Electric Reliability Council (NERC) regions. It includes submodels that determine, in sequence, energy demand, peak power demand, capacity requirements, generation energy requirements, fuel demands, financial requirements, and electricity prices. The demand model calculates electricity demand and dispatched electric energy by means of a set of econometric equations that quantify the relationship between electricity use and economic activity including, household formation, commercial employment and electric intensive industrial output. However, in the EMF exercise no price feedback to the demand model was used. Appendix B includes a more detailed description of the DRI model. ${ }^{8}$

The DRI model uses a high level of regional detail. For example, the model distinguishes between dispatched electric energy from utility sources (or under agreement from non-utility sources) and cogeneration or imports. The model includes a rate base inventory of all generation,

\footnotetext{
${ }^{6}$ Farney et al.
}

${ }^{7}$ Eynon, Robert T. and Lessly Gouadarzi, "Analysis of Nonutility Electric Generation," U.S. Department of Energy, Energy Information Administration, 1989.

${ }^{8}$ Larry Makovich, "DRI Energy Analysis of OTA's Deregulation Scenario 4: All Source Competition for All Bulk Power Supplies with Generation Segregated from Transmission and Distribution Services," DRI Energy Group, Lexington, MA, February 22, 1988. 
transmission, and distribution assets. For purposes of the EMF analysis, DRI modified a number of assumptions routinely employed in the model in order to characterize the alternative economic and regulatory scenarios. For example, in order to simulate OTA scenario number four, the investor- owned portion of generation was separated from the rate base inventory as of the forecast year 1990. In the DRI analysis for EMF, only publicly owned generation assets and all transmission and distribution assets were included in the rate base after 1990.

In the DRI model one mechanism for characterizing deregulation is to revalue assets. The construction and financing costs of new generation were assumed to be identical for utility and non-utility power producers. The model computes the long run marginal cost of new generation as a weighted average of the least cost future technology mix (using the so-called "peaker method"). These costs are calculated for each region regardless of whether utility or non-utility power producers build or operate the capacity. Incremental capacity costs are modified upward or downward to approximate market clearing capacity payments, which reflect the degree of generating capacity shortage or surplus in each region. ${ }^{9}$ In the EMF analysis for scenarios in which only new generation is deregulated, the model revalues the new generating capacity at market clearing capacity payments while retaining all past assets in the rate base (along with public power, transmission, and distribution) valued at historic embedded costs. Under full deregulation, all generation assets are revalued at their replacement costs.

Another mechanism used by the DRI model to characterize deregulation is to price electric energy as if it operated in a spot market, e.g., valuing hydroelectric power not on variable operating costs but rather at the cost of the marginal operating unit (the average system lamda).

${ }^{9}$ Makovich, 1988, up.cit. 


\section{AES FOSSIL2}

FOSSIL2 is a dynamic simulation model of U.S. energy supply and demand. It was first used in 1978 and has been used since then in support of the U.S. Department of Energy's biennial submission to Congress of the National Energy Plan. The model provides long term (20-40 year) forecasts of U.S. energy supply and demand. Appendix C includes a more detailed description of the model structure. For purposes of the EMF exercise, the electricity sector of FOSSIL2 is the focus. ${ }^{10}$

FOSSIL2 operates by first projecting demand for energy services (heat, light, steam, and shaft power) in each end-use service category. The model then calculates the share of service demand captured by end-use technologies such as conventional steam generation, cogeneration, and conservation. The end-use market shares then determine a derived demand for electricity: the load that utilities must supply in the future. The electricity supply "module" of FOSSIL2 then estimates the necessary commitment to new generating capacity (or purchases from non-utility sources), the utilization of existing capacity, and the corresponding revenue requirements and electricity rates to customers.

For purposes of the EMF analysis, the model was modified to permit accounting of generation capacity and other assets according to alternative economic and regulatory scenarios. In particular, some scenarios require electricity prices to be determined under traditional rate regulation directly from system costs and a regulated rate of return. In some scenarios, prices are set under new rules: in one scenario (scenario 3), new generation is priced competitively at long-run marginal cost under long-term (15-30 year) contracts. Finally, under total deregulation of generation (scenario 4), old assets are revalued so that all generation is priced at marginal cost.

The modifications to the FOSSIL2 electricity supply sector also include a variety of non-utility generation technologies and costs. In particular, the DRI model assumes no difference

${ }^{10}$ Roger F. Naill and Sharon Belanger, "An Analysis of the Impacts of Deregulation of the U.S. Electric Utility Industry," AES Corporation, July 18, 1989. 
in the construction or financing costs between independent power producers and utilities. The AES model assumes a 10 percent reduction in generation costs for independent power producers relative to utilities, attributable to assumed lower financing, capital, and fuel costs as well as increased plant availability (see Table 2). FOSSIL2 also assumes that technology choices for nonutility suppliers are wider than that for utility suppliers, including projects using standard pulverized coal (PC) boilers, circulating fluidized-bed coal boilers (CFBC), integrated coal gasification combined cycle (IGCC), and small power producer technologies such as wind, biomass, or small hydropower projects.

FOSSIL2 includes a demand feedback loop in which the calculated electricity rates are used by the "demand module" to estimate load growth. Hence the impact of the alternative economic and regulatory scenarios on load growth are taken into account in the analysis.

\section{Model Results and Comparisons}

The key results of the modeling exercise for DRI and AES models are illustrated in Figures 1 and 2 , respectively. The DRI model was run only for a scenario in which $-1 !$ generation is deregulated, i.e., in which generating assets are revalued at marginal cost and energy is revalued at spot market prices. The AES model was run for four of the five alternative OTA scenarios (see Table 1). Only Scenario 2, where the key feature is mandatory transmission access, is left out since the model does not include an accounting of transmission constraints.

For the comparable scenario, full deregulation of all generation (Scenario 4), the AES and DRI models both produced qualitatively similar results. Both models suggested that full deregulation would create a producer "windfall," where electricity prices adjust abruptly from their current levels based on embedded costs to a higher level based on long-run marginal costs.

In the DRI model, full deregulation resulted in a price "50 to 100 percent higher that in the base" (DRI 1988, p. 2). DRI's price as modeled for Scenario 4 (full deregulation) was based on 


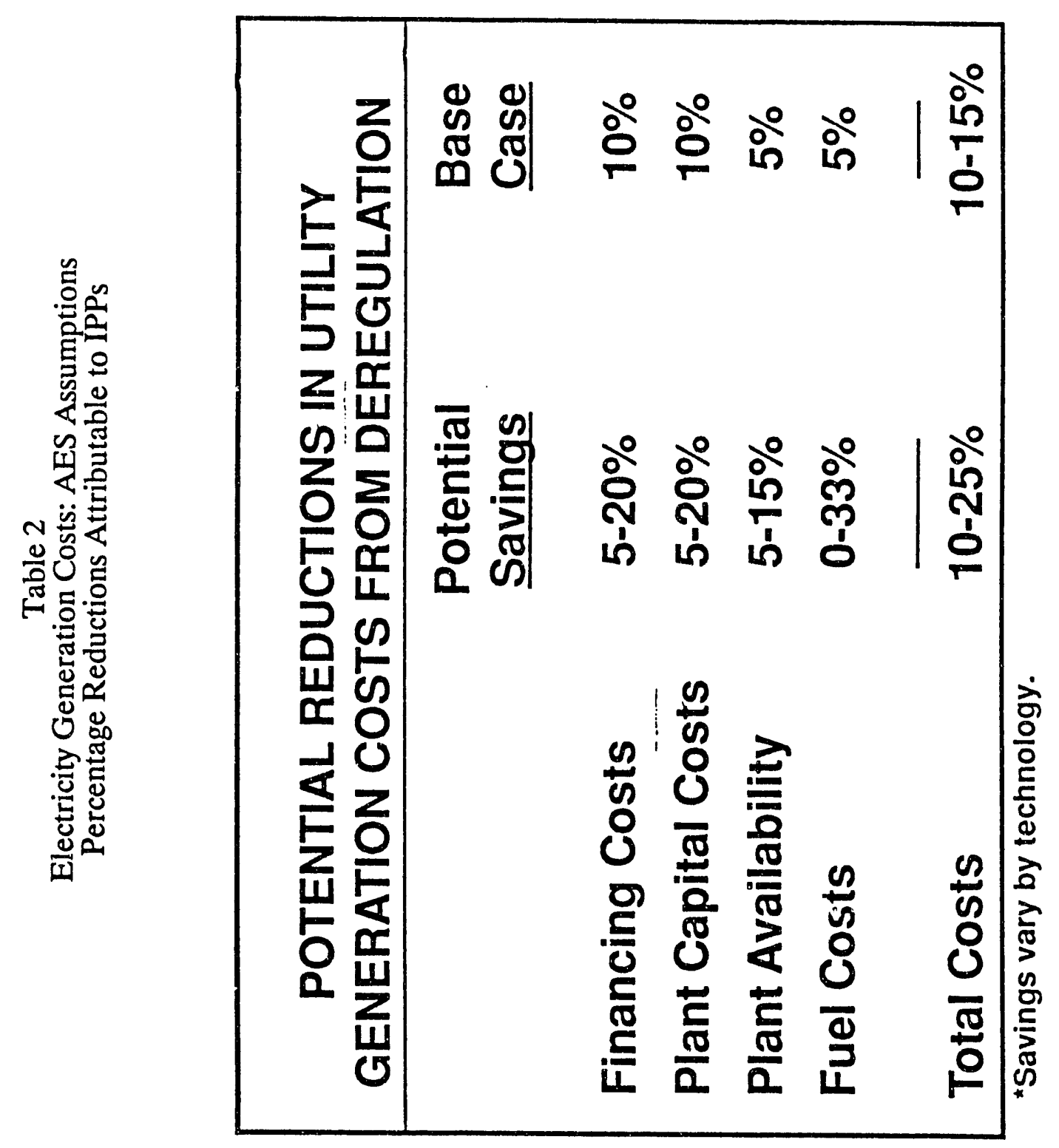


Figure 1

Electricity Price Under Deregulation of Generation: DRI Model

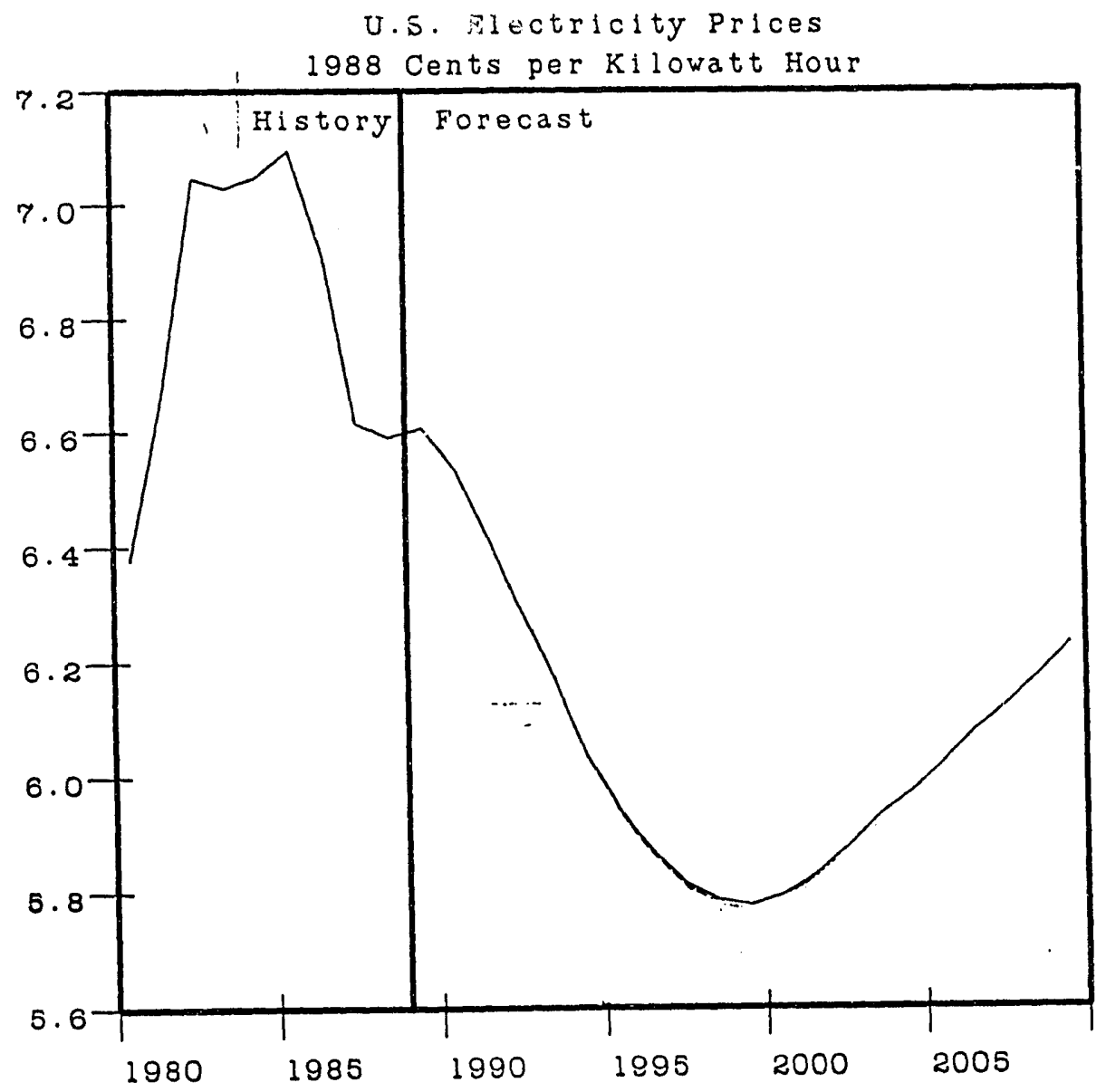




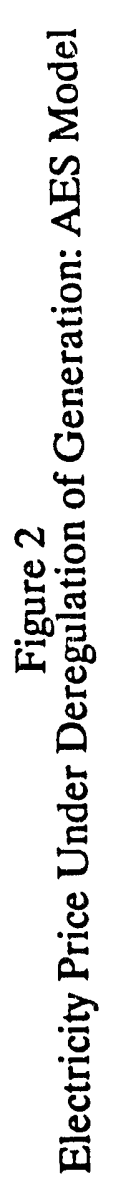

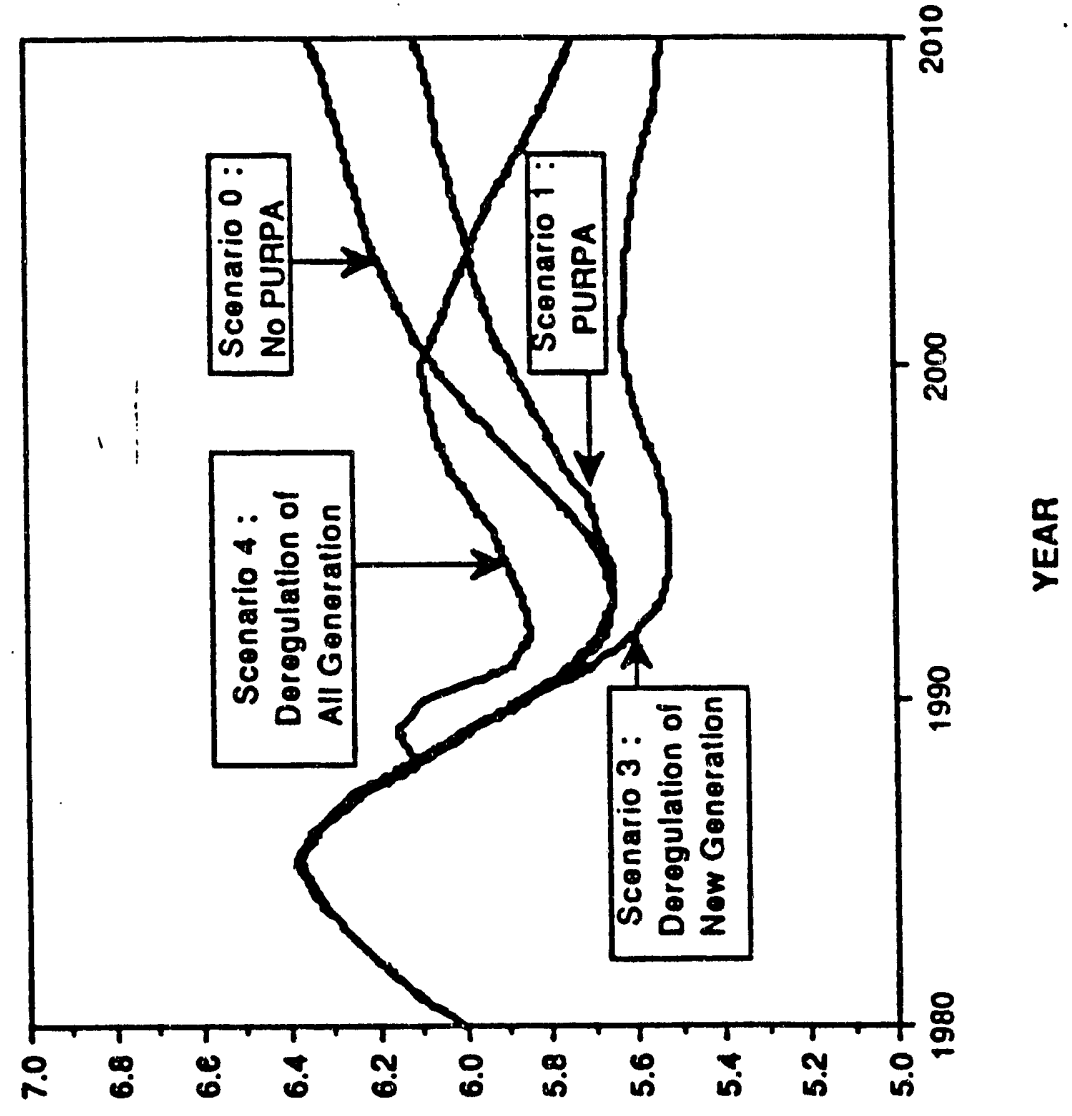

HMYO 8861 
long-run marginal costs. Long-run marginal costs were developed for capacity based upon replacement value. Long-run marginal costs were further modified upward or downward to reflect the degree of generating capacity shortage or surplus in each region. The deregulation price encompassed only generation costs; transmission and distribution continued to be included as in historic embedded costs because they were not deregulated in this scenario.

In the AES model, full deregulation resulted in a 10 percent increase in electricity prices. The same basic market mechanism was at work as in the DRI analysis: prices increased as existing utility generation assets were revalued upwards. These assets are now regulater' , heir book value, and current electricity prices reflect this value (estimated at an average of about $\$ 400 /$ kilowatt in 1988 dollars). In the AES analysis, deregulation results in existing generation assets being revalued somewhere between book value $(\$ 400 / \mathrm{kW})$ and market value (roughly $\$ 1,100 / \mathrm{kW}$ in 1988 dollars), resulting in a 0.6 cents $/ \mathrm{kWh}$ (or 10 percent) increase in average U.S. electricity prices.

While the basic "behavior mode" from both models is the same (full deregulation results in a price jump), the magnitude of the price increase is different between the two models. Since both groups modeled full deregulation in the same way (prices are set equal long-run marginal costs), the difference in the size of the price increase likely stems from a difference in what constitutes long-run marginal costs. After some discussion, the analysts responsible for the two models agreed that the rajajor difference rests on whether, after full deregulation, the industry would determine prices by using a "spot" market or would rely more on long- term contracts. The DRI model takes a "spot market" approach, which results in large price windfalls in the $1990-2000$ period when there is a shortage of electricity (similar to the WSCC experiment on spot market pricing). The AES analysis assumes that generators will sign long-term contracts, and the potential short-run windfalls (or losses) due to mismatches of supply and demand would be mitigated. Spot market pricing would tend to make the behavior of electricity prices more volatile 
under deregulation and is a separate issue worth examining if price deregulation is considered as a serious policy option.

AES also tested the effects of scenarios other than full deregulation. Specifically, Figure 2 also shows the effects of the Public Utilities Regulatory Policy Act (PURPA) of 1978, which in effect partially deregulated new generation capacity. This law was responsible for the existence of "Qualifying Facilities"--cogenerators and small power producers who are independent from traditional utilities and are unregulated (more generally called the independent power industry). Non- utility generators (NUG: tre assumed in the AES analysis to have lower costs (see Table 2). The lower costs come from competition: unregulated generation companies work creatively to lower their capital, financing and operating costs in order to gain a competitive market advantage. The result is that a large fraction of the market for new generation is captured by NUG's, which lowers average electricity prices (the AES analysis show prices 2 to 3 percent below a scenario 4 because deregulation affects only new generation--not all generation. Because new generation is offered at a lower price in this scenario, average electricity prices are gradually lowered.

Scenario 3 (deregulation of new generation) creates results very similar to Scenario 1 , except competition for new generation is intensified--resulting in lower prices than in Scenario 1. A new type of market player, the independent power producer or IPP, is added in this scenario, allowing non-utility generation to capture a larger market share than with PURPA alone (Scenario 1). Prices in this case are 5 percent lower than the base case.

\section{$\underline{\text { Sensitivity Analysis }}$}

Both DRI and AES completed a number of sensitivity runs of models to determine the degree to which differences in major assumptions could explain the differences in results. For example, a critical assumption in the AES analysis is that deregulated (competitive) generation 
will have lower costs than regulated generation. In fact, it is the goal of deregulation to capture this "efficiency gain" through market mechanisms that lower prices by increasing competition. Figures $3 a$ and $3 b$ test the behavior of the AES deregulation results under two alternative assumptions about regulated versus deregulated generation costs: first, an assumption that regulated and deregulated generation costs are the same, and a second case where deregulated generation costs are 20 to 25 percent lower than with regulated utility generation (the base case assumes 10 to 15 percent lower costs).

If the costs of generation are the same whether the industry is regulated or deregulated, there are no efficiency gains to capture under deregulation. Deregulation of new generation (Scenario 3) therefore results in prices essentially the same as in the base case (see Figure 1). With a 20 percent reduction in costs from deregulation, the potential benefits from deregulation are larger: possibley 10 percent lower average costs (the average decrease is less than 20 percent because only new generation is affected).

Furthermore, the potential "windfall" effects of total deregulation. With total deregulation, the price of existing generation goes up while the price of new generation goes down in the base case AES run. If there is no cost advantage from deregulating new generation, the only effect on price is the "windfall" price increase for existing generation (see Figure 2). However, a large cost advantage from new generation can effectively offset the effect of "windfall" profits on existing generation (see Figure 4b). Electricity deregulation is more or less attractive in direct proportion to the potential cost reductions that might be associated with deregulation and competition. Figure 2 shows the implications of deregulating all generation (new and old, Scenario 4) versus only new generation (Scenario 3) using the AES model.

Figure 5 shows the DRI model sensitivity to the marginal costs of new generation for their base case forecast. The results are relatively insensitive these costs. The explanation may have to do with the scale of marginal investments relative to the installed base of generation assets. 


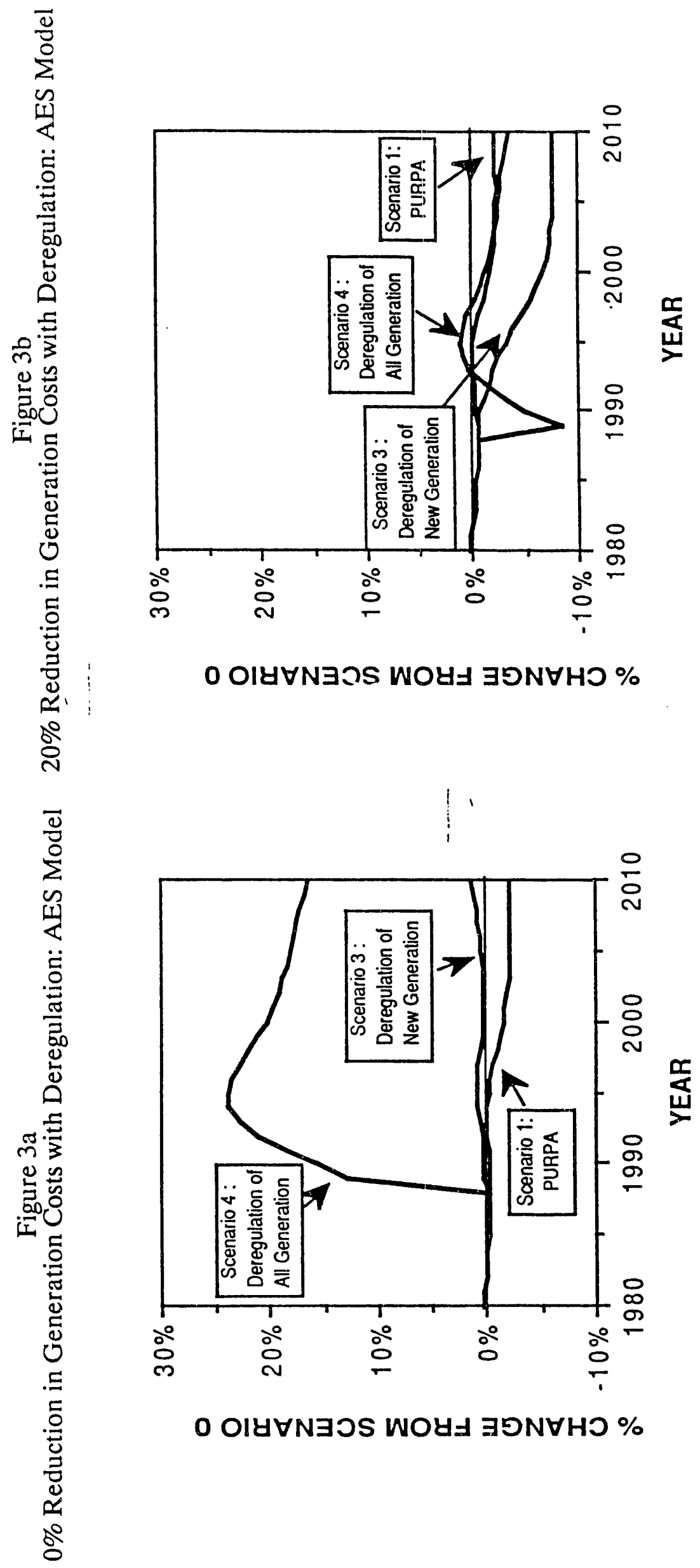




$$
\overline{I E}
$$


Even with very large decreases in marginal costs of new capacity (5-10 percent as shown in the figure) are not likely to affect average electricity price very much unless the existing assets are revalued as well, as in Scenario 4. For the DRI base case, there was only an 8 percent increase in installed capacity between 1990 and 1995 and a 22 percent increase by 2010 , even with modestly aggressive accounting of capacity retirement.

AES also completed a sensitivity analysis of their results to the price feedback effect, which generally was not substantial -- on average only several percent change from the base case scenarios.

The differences in the results for Scenario 4, full deregulation, between the FOSSIL2 and the DRI model appear to be rooted principally in the implementation of scenario assumptions. In particular, DRI's two mechanisms for implementing full deregulation are revaluing generation assets at marginal capacity costs and revaluing delivered electrical energy at spot market prices. FOSSIL2 adopts only the first of these two assumptions which considerably moderates the rate at which the electricity price under Scenario 4 . Neither model, nor any other that we reviewed in the course of EMF 10, is very well equipped at this point to deal with the likely practical constraints hat would accompany any scenario of increased competition, such as transmission capacity, existing rate base constraints, limited procurements for new capacity, etc.

\section{CONCLUSIONS}

Existing electricity policy models need considerable enhancement to address many of the major issues associated with increasing competition in the electric power industry. Nonetheless, while only a few of the major issues related to increased competition have been addressed with models to date, many of these issues could be modelled. Moreover, even existing models can address some of the central issues, such as possible price paths of electricity during the transition from the current trends in the industry to alternative, more market-oriented industry structures. 
However, many of the issues that we were able to analyze in the course of the EMF 10 exercise are very sensitive to basic assumptions about economic growth, marginal generation costs, and demand elasticity.

Despite the relatively small number of models for this exercise and the inherently large amount of uncertainty involved in modeling structural change in an industry, the modeling results seem to support the following conclusions:

1. Deregulating electricity prices could result in higher rather than lower prices over the next 10-20 years. Both the DRI and AES analyses suggest that complete deregulation of generation (Scenario 4) would increase electricity prices significantly (10-100 percent) in the near term.

2. On the other hand, policies that increase competition for new generation capacity will likely lower electricity prices (see AES results in Figure 2). This conclusion depends critically on whether competitive markets can offer lower-cost generation options compared to regulated markets.

3. Both the AES and DRI modeling runs suggest that full deregulation including revaluing of existing assets creates precipitous, perhaps turbulent changes in the structure of the industry and electricity prices. Deregulation of new generation, as one might expect, more gradual and orderly changes in the industry and in electricity prices.

Finally, this exercise also confirmed that of particular concern regarding the use of any policy models, or more specifically of incorporating engineering models into a policy modeling framework, is the lack of suitable data. For example, including transmission will be perhaps the most challenging enhancement to the existing generation of models, but current data do not exist to characterize the possible operating ranges of the existing transmission network. ${ }^{11}$

${ }^{11}$ Line ratings, individual component limitations, and other data exist but are not very useful by themselves. If operating system conditions constrain the use of lines for other reasons such as parallel path flows, stability, contingency security, or even maintenance, much more information about the way the transmission system is operated is necessary to evaluate the implications of proposals that might affect system operation. 
most challenging enhancement to the existing generation of models, but current data do not exist to characterize the possible operating ranges of the existing transmission network. ${ }^{11}$

${ }^{11}$ Line ratings, individual component limitations, and other data exist but are not very useful by themselves. If operating system conditions constrain the use of lines for other reasons such as parallel path flows, stability, contingency security, or even maintenance, much more information about the way the transmission system is operated is necessary to evaluate the implications of proposals that might affect system operation. 

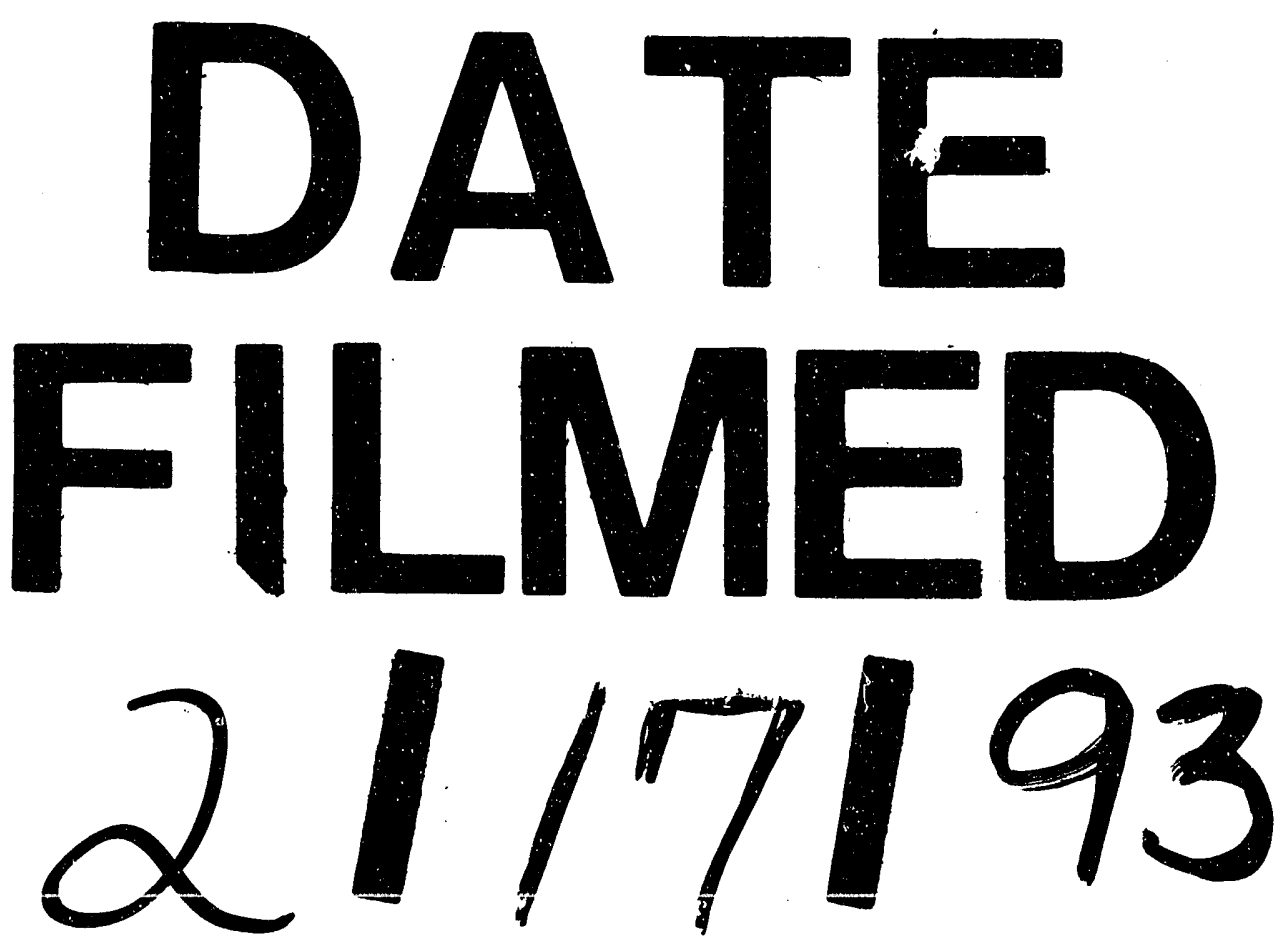


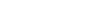

